\title{
Dielectric relaxation in calcium titanate-containing ceramics prepared by plasma spraying
}

\author{
Pavel Ctibor $^{\mathrm{a}, *}$, Josef Sedláček ${ }^{\mathrm{b}}$, Karel Neufuss ${ }^{\mathrm{a}}$, Pavel Chráska ${ }^{\mathrm{a}}$ \\ ${ }^{a}$ Materials Engineering Department, Institute of Plasma Physics, Academy of Sciences of the Czech Republic, 18221 Prague 8, Czech Republic \\ ${ }^{\mathrm{b}}$ Department of Mechanics and Materials Science, Faculty of Electrical Engineering, Czech Technical University, 16627 Prague 6, Czech Republic
}

Received 22 January 2003; received in revised form 25 February 2003; accepted 12 March 2003

\begin{abstract}
The relative permittivity and loss factor frequency dependence in a weak electric field of plasma sprayed perovskite and ilminite polycrystalline ceramic materials - pure synthetic calcium titanate, as well as magnesium titanate - calcium titanate mixture, were studied. It was observed that plasma-sprayed titanates exhibit a strong relaxation of permittivity and loss factor decrease when they are measured in an as-sprayed state. The frequency dependence of the earlier properties is influenced by chemical composition and spraying parameters, but the relaxation character in general is preserved in all cases. The volume resistivity of the samples in an assprayed as well as subsequently annealed state was studied also. Several aspects of the structural features of plasma deposits and their possible influence on dielectric properties are discussed.
\end{abstract}

(C) 2003 Published by Elsevier Ltd and Techna S.r.l.

Keywords: B. Microstructure-final; C. Electrical properties; D. Perovskites; E. Insulators

\section{Introduction}

Some particular works on the subject influence of plasma spraying on dielectric properties of ceramics have been published [1-4], but there is small amount of results comparing plasma-sprayed samples with sintered analogs. It is desirable to select a high-permittivity linear dielectric with a simple character of dielectric response at normal conditions and at the time a material whose structure is not influenced by plasma spraying - neither chemical nor phase composition. Only with such an arrangement can there be a positive prospect to gain relevant knowledge about this topic.

As an example of the earlier described requirements fulfilling and moreover relatively chemically simple material, calcium titanate was selected. This materialsynthetic perovskite $\left(\mathrm{CaTiO}_{3}\right)$ and its mixture with synthetic geikielite $\left(\mathrm{MgTiO}_{3}-\mathrm{CaTiO}_{3}\right)$ were studied by the authors in recent years. First of all, they were examined from the point of view of their sprayability, chemical as

\footnotetext{
* Corresponding author. Tel.: +42-266053727; fax: +42286586389.

E-mail address: ctibor@ipp.cas.cz (P. Ctibor).
}

well as phase composition, microstructure [5] and mechanical [5] as well as thermal properties [6]. Additional work resulted in a basic study of selected dielectric properties [7].

Dielectric behavior of $\mathrm{CaTiO}_{3}$ is described in several comprehensive textbooks [8,9]. It is referred that its relative permittivity is independent of temperature in the frequency from $10^{2}$ to $10^{8} \mathrm{~Hz}$ while the constant value is between 115 and 180 in dependence on chemical purity, sintering conditions and measurement techniques [8]. In Ref. [9], the graphs expressing loss factor dependence of frequency are given. A small drop in the whole frequency range is reported there in the graphs by one author but an increase above $10^{5} \mathrm{~Hz}$ by another. $\mathrm{MgTiO}_{3}$ is one dielectric whose dielectric behavior can easily be controlled by the addition of $\mathrm{CaTiO}_{3}$. An $\mathrm{MgTiO}_{3}$ $\mathrm{CaTiO}_{3}$ mixture is reported in Ref. [10]; but only its components are described in detail elsewhere [8,9]. A mixture of $\mathrm{MgTiO}_{3}$ and $\mathrm{CaTiO}_{3}$, with the ratio equal to $94: 6 \mathrm{wt} . \%$ (in this paper the label MCT is used) has a permittivity independent of temperature in a wide range of frequencies $[8,10]$. This material is used as a low-loss microwave dielectric in a sintered state. 


\section{Experimental}

\subsection{Materials selection and preparation}

Both materials were obtained in the form of tablets of industrial purity, produced by the sintering of micropowders. The synthetic form of perovskite $\mathrm{CaTiO}_{3}$ is produced by reactive sintering of $\mathrm{CaO}$ and $\mathrm{TiO}_{2}$. $\mathrm{CaTiO}_{3}$ powder used for experiments was sintered without any additives, normally used for decreasing the sintering temperature. Tablets were crushed and sieved into a powder of the correct size for spraying.

\subsection{Plasma spraying}

The samples were manufactured using a highthroughput water-stabilized plasma spray system WSP ${ }^{\circledR}$ (PAL 160, Institute of Plasma Physics, Prague, Czech Republic) [11]. This system operates at about $160 \mathrm{~kW}$ arc power and can process high amounts of material. This system can be used to fabricate deposits similar but not identical to those prepared by means of conventional atmospheric plasma-spray systems based on gas-stabilized torches [12]. Two spraying distances (SD) 350 and $450 \mathrm{~mm}$ were used to spray present samples for observation of the influence of this parameter on the studied properties. Spraying distance is one of the main parameters that can affect the spraying process - its efficiency as well as deposit's character. As substrates flat carbon steel as well as stainless steel coupons were used. The feedstock had size 63-125 microns; the powder was fed in by compressed air through two injectors. The deposited thickness was about $1 \mathrm{~mm}$ for coatings and $2.5 \mathrm{~mm}$ for subsequently stripped deposits. Thick deposits were stripped from the substrate by a releasing agent or by thermal cycling between approximately +200 and $-70{ }^{\circ} \mathrm{C}$.

\section{Measurements}

\subsection{Specimen preparation}

The surface of specimens was ground after spraying to eliminate roughness, which is an inherent property of plasma sprayed coatings. There exist two types of specimen. The first one is stripped-out from the substrate and ground from both sides to produce planparallel plates with a smooth surface. Such specimens are in principle monoblock capacitors with dimensions $10 \times 10 \times 1 \mathrm{~mm}$. The second type is a coating on the metallic substrate. In this type only the topside was ground. A thin layer of aluminum as the electrode (at planparallel plates from both sides) was sputtered in reduced pressure on the ground surface.

Reference specimens were prepared by sintering previously calcinated powder. Sintering as well as annealing of plasma-sprayed deposits was carried out in a laboratory furnace at different temperatures typically for $2 \mathrm{~h}$ in an air atmosphere. Heating as well as cooling speed was $7^{\circ} \mathrm{C}$ per minute in all cases.

\subsection{Description of the electric measurements}

Electric measurements were carried out in Prague at the Czech Technical University's Faculty of Electrical Engineering, Department of Mechanics and Materials Science, Czech Republic. The electric field was applied parallel to the spraying direction (i.e., perpendicular to the substrate surface).

Capacity was measured in the frequency range from $200 \mathrm{~Hz}$ to $1 \mathrm{MHz}$ using a programmable LCR-meter (PM 6306, Fluke, USA). The frequency step was smaller at lower frequency and progressively larger at higher one. Applied voltage was $1 \mathrm{~V} \mathrm{AC}$; the stabilized electric source was equipped with a micrometric capacitor as recommended in the relevant standard [13]. Relative permittivity $\varepsilon_{\mathrm{r}}$ was calculated from measured capacities and specimen dimensions [14]. This same LCR-meter (PM 6306) was used for the loss factor measurement. Loss factor $\operatorname{tg} \delta$ was measured at the same frequencies as capacity. Electric resistance was measured with a special adapter-model 6105-to fulfill ASTM recommendations [15]. The electric field was applied by a regulated high-voltage supply and the values read by an electrometer (617C, Keithley Instruments, USA). Applied voltage was $100 \pm 2 \mathrm{~V}$ DC. Volume resistivity was calculated from the measured resistance and specimen dimensions [14]. The values (in the text denoted as "sample") are from an average of 3-6 specimens.

\section{Results and discussion}

\section{1. $\mathrm{CaTiO}_{3}$}

Fig. 1 shows that permittivity of sintered $\mathrm{CaTiO}_{3}$ is frequency-independent. Fig. 1 also shows that the assprayed sample from a spraying distance of $350 \mathrm{~mm}$ (SD350) has very high relative permittivity at low frequencies less than $200 \mathrm{kHz}$. The permittivity is strongly frequency-dependent and it does not drop below the "sintered value". The sample from the spraying distance of $450 \mathrm{~mm}$ (SD450) starts with a relative permittivity of about 220 at $200 \mathrm{~Hz}$ and therefore the permittivity drop is smaller-but both samples do not have the same value at $1 \mathrm{MHz}$. Up to $1 \mathrm{MHz}$ relative permittivity is probably further less dependent on spraying distance and becomes the same value as sintered calcium titanate. It indicates that in the case of as-sprayed deposits plays a role some polarization mechanism, which is associated with features regulated by spraying distance [14]. This mechanism does not disappear completely below $1 \mathrm{MHz}$. 


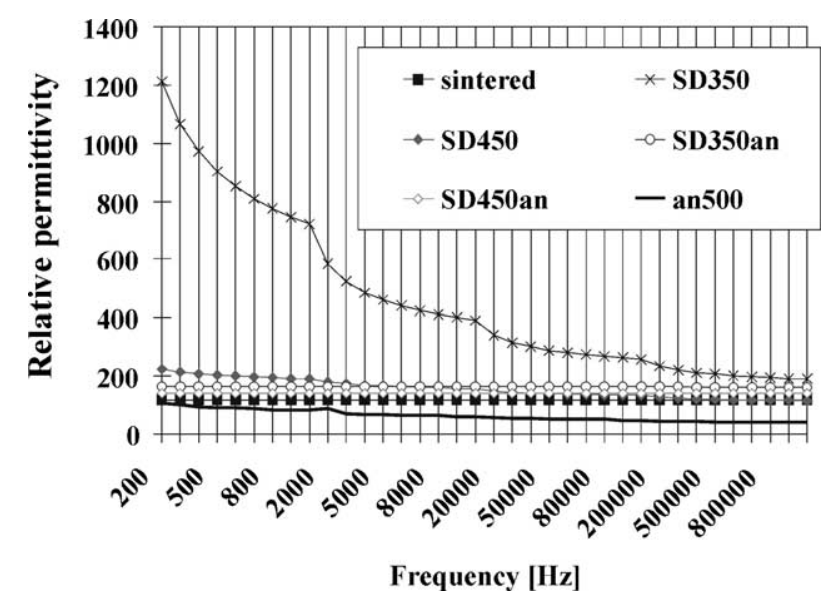

Fig. 1. Relative permittivity of $\mathrm{CaTiO}_{3}$. Sintered as-sprayed $(\mathrm{SD}+$ spray distance in $\mathrm{mm})$ and deposits $\mathrm{SD}$ annealed at $1250{ }^{\circ} \mathrm{C}(\mathrm{an})$.

The annealing of as-sprayed plasma deposits leads to the disappearance of relaxation behavior. A sample of the deposit from SD $350 \mathrm{~mm}$ annealed at $500{ }^{\circ} \mathrm{C}$ for $2 \mathrm{~h}$ (sample an500 in Fig. 1) preserves a certain relaxation, which is comparable to an as-sprayed sample from SD $450 \mathrm{~mm}$, but shifted to a lower permittivity in the whole frequency range. The deposits annealed at $1250{ }^{\circ} \mathrm{C}$ for 2 $h$ in air environment (SD350an and SD450an) have both frequency-independent permittivity as common in the case of sintered ceramics. This fact is consistent with expectations that the annealing temperature is very important. (Please note that the uncertainty is about $15 \%$ of the nominal value due to non-parallelity of surfaces covered by $\mathrm{Al}$ electrodes.)

In Fig. 2, the loss factor dependence on frequency for as-sprayed and annealed calcium titanate is given. The most significant is an extremely high loss factor of the deposit from a spraying distance SD $350 \mathrm{~mm}$. Also the deposit annealed at $500^{\circ} \mathrm{C}$ as well as deposit SD 450 has abnormally high losses. Annealing of as-sprayed deposits

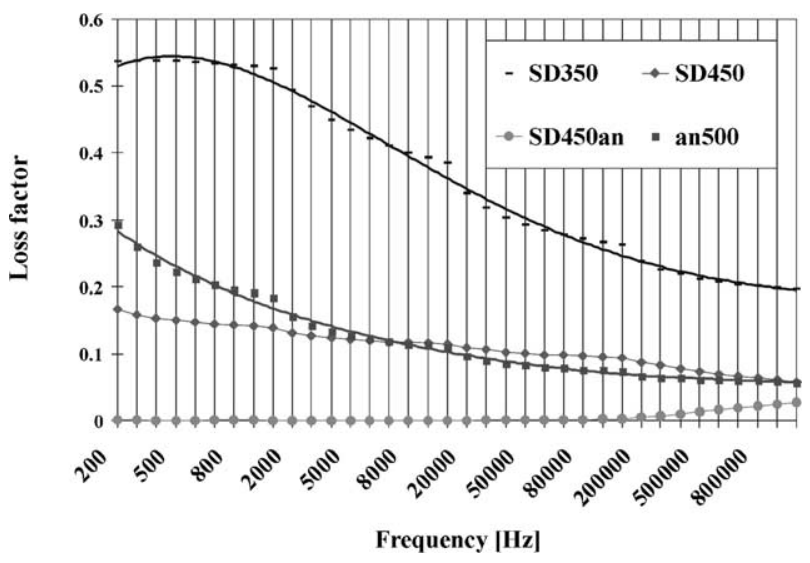

Fig. 2. Loss factor of $\mathrm{CaTiO}_{3}$. As-sprayed (SD), annealed at $500{ }^{\circ} \mathrm{C}$ (an500) and SD 450 annealed at $1250{ }^{\circ} \mathrm{C}$ (SD450an). at higher temperature leads to a decrease of the loss factor, but there is not a well-pronounced difference between both SDs and therefore only sample 450an is included.

A combination of permittivity and loss factor indicates that both polarization and conductive losses in deposits have extremely high values at low frequencies and it is impossible to suppress conductive losses and preserve polarization at the spraying process. Plasma spraying as a very speedy thermal process creates materials with non-equilibrium structure in which there is not enough time for diffusion development. An example of the as-sprayed microstructure can be seen in Fig. 3.

Regarding $\mathrm{CaTiO}_{3}$ neither chemical nor phase changes were observed after spraying [5,14]. Therefore probably a feature of grain boundaries, at the present time not well understood, is allowed to be responsible for relaxation effects.

\section{2. $\mathrm{MCT}\left(\mathrm{MgTiO}_{3}-\mathrm{CaTiO}_{3}\right)$}

Results gained on this system are more difficult to evaluate because of chemical and phase changes introduced into the material by spraying $[5,14]$. But a more comprehensive study of the deposit's annealing was performed on this material because of its lower melting point and sintering temperature. Only one spraying distance SD $400 \mathrm{~mm}$ was used.

Fig. 4 shows the dependence of annealed versus the sintered MCT relative permitivity ratio eps(a)/eps(s) on annealing temperature in the whole thoroughly studied frequency range. The annealing temperature is expressed as annealing versus sintering temperatures ratio $\mathrm{Ta} /$ $T \mathrm{~s}$ on a horizontal axis. A temperature of $1250{ }^{\circ} \mathrm{C}$ is used here as a sintering temperature of MCT powder, whereas it is considered to be equal to the melting point multiplied by the factor 0.75 .

It can be seen that an as-sprayed deposit exhibits relaxation of relative permittivity in a similar manner as

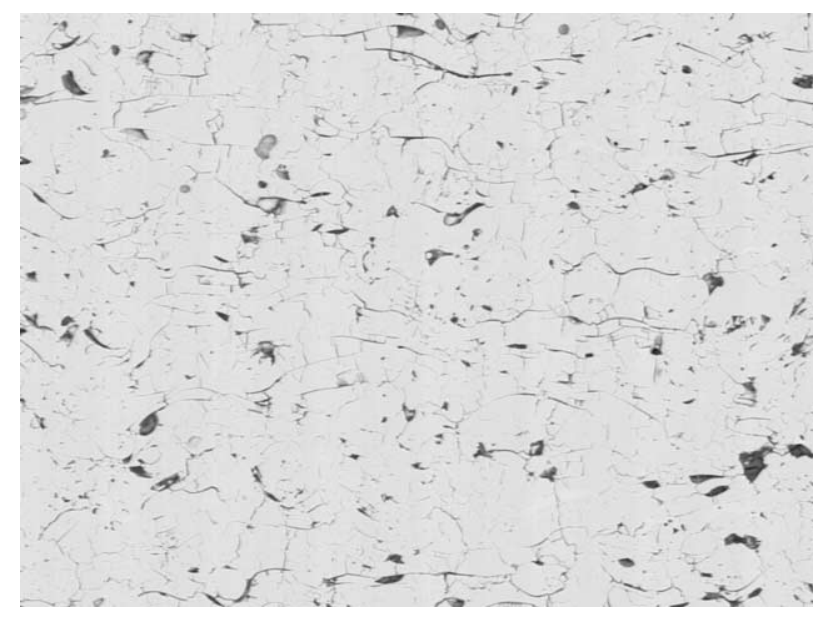

Fig. 3. Structure as-sprayed $\mathrm{CaTiO}_{3}$. Cross-section, light microscopy, image width corresponds to $0.36 \mathrm{~mm}$. 


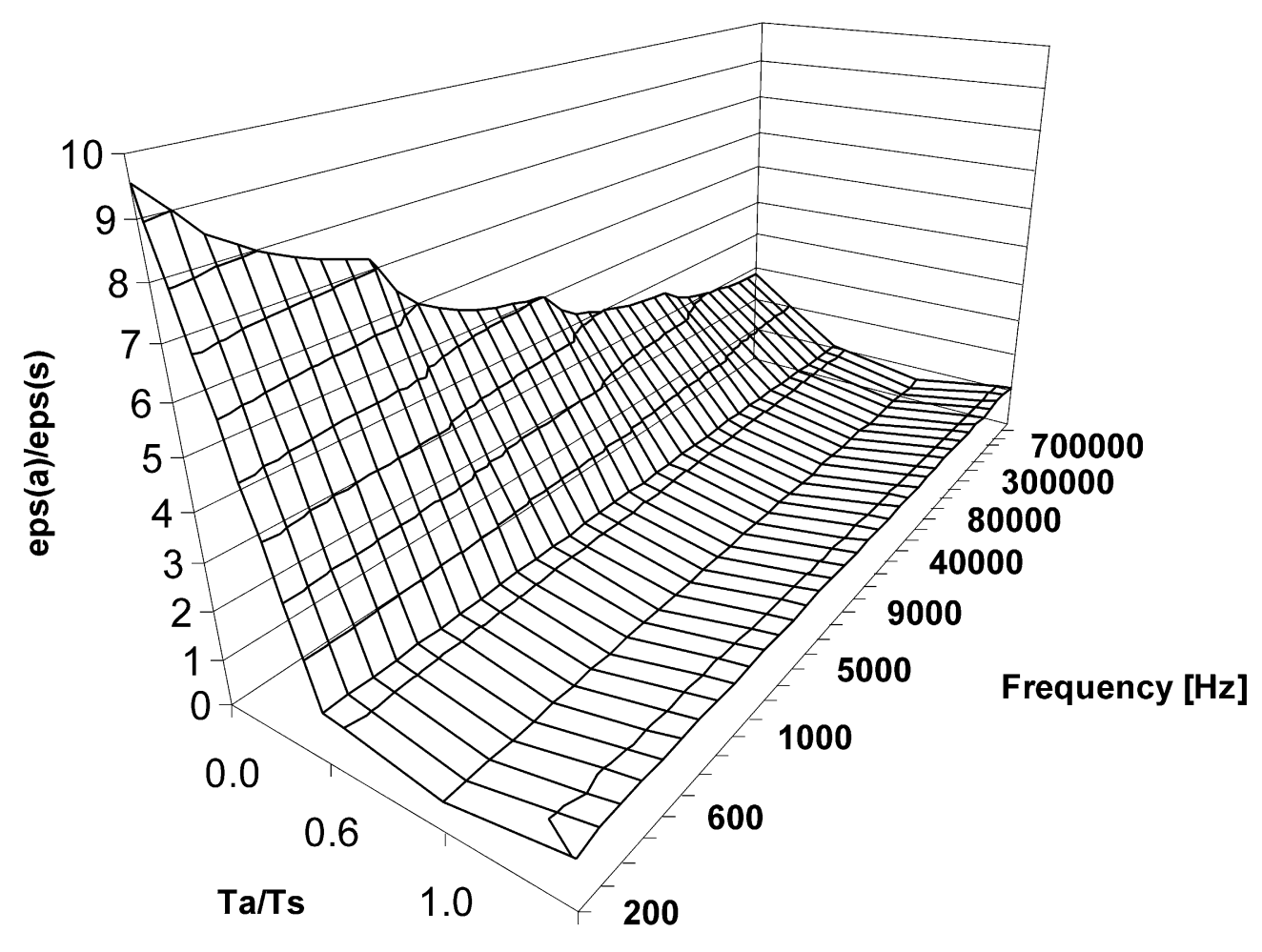

1.2

Fig. 4. Relative permittivity of annealed plasma deposit versus sintered MCT ceramics - eps(a)/eps(s) in dependence on annealing temperature expressed as annealing versus sintering temperature $(T \mathrm{a} / T \mathrm{~s})$ and frequency.

previously discussed $\mathrm{CaTiO}_{3}$ perovskite. Annealing at $T \mathrm{a} / T \mathrm{~s}=0.6$ leads to a rapid decrease of permittivity - it has the same value as sintered MCT $\left(\varepsilon_{\mathrm{r}}=\right.$ approximately 20) and also as plasma deposit annealed at a sintering temperature (represented by the curve $T \mathrm{a} / T \mathrm{~s}=1$ ). An additional increase of annealing temperature $(\mathrm{Ta} /$ $T \mathrm{~s}=1.2)$ preserves this value. Interesting is the fact, that the permittivity value is stable in the entire frequency range. In combination with loss factor results (Fig. 5) it indicates that polarization mechanisms in the deposits annealed at high temperatures should be the same as in sintered ceramics and not as in as-sprayed deposits. Fig. 5 shows loss factor measurement results in the same temperature and frequency coordinates as relative permittivity. The only difference is that on the vertical axis the absolute values of the loss factor $\operatorname{tg} \delta$ are given instead of the ratio. The loss factor of the as-sprayed deposit is extremely high in the whole range of frequencies. Annealing decreases rapidly the loss factor value also in the whole range of frequencies.

\subsection{Volume resistivity of studied materials and their implications}

Volume resistivity was calculated from the measured resistance and specimen dimensions. Results are summarized in Table 1. Plasma deposits exhibit volume
Table 1

Volume resistivity results $[\Omega \mathrm{m}]$

\begin{tabular}{llllll}
\hline Material & As-sprayed & $\begin{array}{l}\text { Annealed } \\
\text { at } 0.6 \mathrm{Ts}\end{array}$ & $\begin{array}{l}\text { Annealed } \\
\text { at } T \mathrm{~s}\end{array}$ & $\begin{array}{l}\text { Annealed } \\
\text { at } 1.2 \mathrm{Ts}\end{array}$ & Sintered \\
\hline $\mathrm{CaTiO}_{3}{ }^{\mathrm{a}}$ & $1.64 \times 10^{7}$ & n.a. & $1.89 \times 10^{12}$ & n.a. & $1.41 \times 10^{12}$ \\
$\mathrm{MCT}$ & $1.17 \times 10^{7}$ & $3.09 \times 10^{11}$ & $6.88 \times 10^{12}$ & $1.58 \times 10^{13}$ & $7.54 \times 10^{11}$ \\
\hline
\end{tabular}

${ }^{\text {a }} \mathrm{CaTiO}_{3}$ is represented by a deposit from a spraying distance of SD350 mm.

resistivity lower by a $4-5$ order compared with sintered ceramics. Annealing at $0.6 \mathrm{Ts}$ leads to considerable increase of resistivity. After annealing at Ts and above it is possible to make the value comparable with the sintered ceramics or higher.

If this fact is seen in connection with relative permittivity and loss factor results, it could reveal the wellknown fact [16] that conductivity leads to a dielectric loss, which will, however, become unimportant at very high frequency. The influence of the Maxwell-Wagner effect on measured values is described in Ref. [16]. The Maxwell-Wagner effect is obtaining spurious values of relative permittivity due to the conductivity of one component when multi-component material is measured. As an approximation it is possible to match together "static permittivity" with the value measured at $200 \mathrm{~Hz}$ in our experiments as well as "high-frequency 


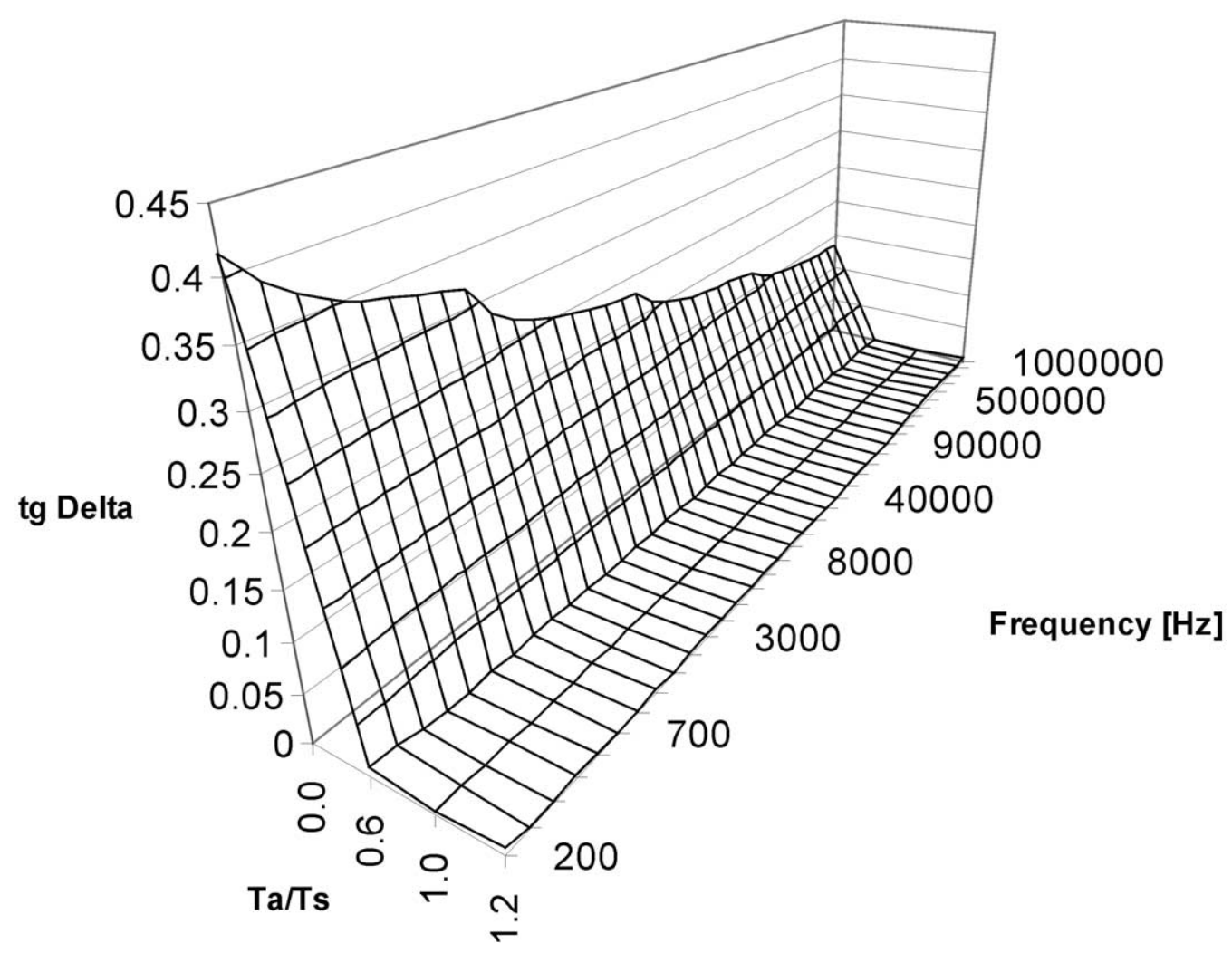

Fig. 5. Loss factor of annealed plasma deposit of MCT ceramics - $\operatorname{tg} \delta$ in dependence on annealing temperature expressed as annealing versus sintering temperature $(\mathrm{Ta} / T \mathrm{~s})$ and frequency.

permittivity" with the value measured at $1 \mathrm{MHz}$. The dispersion of conducting spheres (pores in our case) in a nonconducting matrix (ceramic plasma deposit in our case) is considered in Ref. [16]. The case of pores filled by nonconductive versus conductive medium (dry air versus water) has been proved. The water represents the case that water vapor condensed in voids at deposit cooling. The values in the first and last column of Table 2 were calculated according the two-component dispersion rules described in [16], but application of other rules like the Lichtenecker logarithmic formula [7] in principle gives the same results. The porosity of the deposits used here as water or air content is based on image analysis results [14].

It can be seen that the values in Table 2 in the rows "air in pores" and "water in pores" are similar to those for sintered (also annealed) samples but not to those for as-sprayed. This fact is evident for low as well as for higher frequencies. Table 2 confirms from the point of view of the permittivity-frequency relationship the previously [7] drawn conclusion: there does not exist a medium filling voids (thereby able to penetrate into them during plasma spraying), which could be responsible for the whole magnitude of the difference between permittivity measured on as-sprayed versus sintered samples. The explanation of them probably must be looked for in structural features like grain boundaries arrangement introduced by the plasma spraying process to the material.
Table 2

Influence of Maxwell-Wagner effect on relative permittivity of MCT $\left(\mathrm{MgTiO}_{3}-\mathrm{CaTiO}_{3}\right)$

\begin{tabular}{lcccc}
\hline MCT & $\begin{array}{l}\varepsilon\left(\mathrm{st}^{\mathrm{a}}\right. \\
\text { calculated }\end{array}$ & $\begin{array}{l}\varepsilon(200 \mathrm{~Hz}) \\
\text { measured }\end{array}$ & $\begin{array}{l}\varepsilon(1 \mathrm{MHz}) \\
\text { measured }\end{array}$ & $\begin{array}{l}\varepsilon(\infty)^{\mathrm{b}} \\
\text { calculated }\end{array}$ \\
\hline Plasma sprayed & - & 193 & 54 & - \\
$\quad$ air in pores & 21 & - & - & 10 \\
$\quad$ water in pores $^{21}$ & 21 & - & - & 21 \\
Sintered $^{c}$ & $(20)$ & 21 & 19 & $(19)$ \\
\hline
\end{tabular}

a $\varepsilon$ (st)-static permittivity.

b $\varepsilon(\infty)$-high-frequency permittivity.

c Sintered powder or annealed plasma sprayed deposit.

\section{Conclusions}

It was observed in this paper that plasma-sprayed titanates exhibit a strong relaxation of permittivity when they are measured in an as-sprayed state. The loss factor of as-sprayed deposits has exactly the same character of frequency dependence as relative permittivity, i.e. strong decrease with increasing frequency. This character of losses corresponds with the results found in literature [8], but the absolute values are much higher in the studied case of plasma deposits. The frequency dependence of those properties is impacted by the chemical composition and spraying parameters, but the relaxation character in general is preserved in $\mathrm{CaTiO}_{3}$ as well as in $\mathrm{MgTiO}_{3}-\mathrm{CaTiO}_{3}$ plasma deposits. The 
volume resistivity of the samples in an as-sprayed state is significantly lower than in a sintered state. To obtain an analogous dielectric response to the weak electric field, which bulk ceramics have, annealing at $0.6 \mathrm{Ts}$, where $T \mathrm{~s}$ is sintering temperature, seems to be efficient. Prospective application makes it possible to anneal ceramics together with certain metallic parts of electric circuits. In this way plasma spraying broadens the technological variability in the field of dielectric ceramics. A wide-ranging field for further study is open to find main correspondences between the nature of plasma-sprayed ceramic parts and their dielectric behavior.

\section{Acknowledgements}

This work was supported by the Grant Agency of the Czech Republic under No. 202/03/0708.

\section{References}

[1] C. Friedrich, R. Gadow, A. Killinger, Thermally sprayed multilayer coatings as electrodes and dielectrics in high efficiency ozonizer tubes, in: Proc. of the United Thermal Spray Conference '99, Düsseldorf, Germany, 1999, pp. 676-682.

[2] T. Jansing, R. Fleck, J. Decker, C. Verpoort, Separation and insulating layers of atmospheric plasma-sprayed ceramics for high temperature fuel cells - development and implementation, in: Proc. of the United Thermal Spray Conference '99, Düsseldorf, Germany, 1999, pp. 69-75.

[3] A.H. Dent, et al., Structure-dielectric behavior relationships in
HVOF sprayed $\mathrm{BaTiO}_{3}$, in: C. Berndt (Ed.), Proc. of the First International Thermal Spray Conference, ASM International, Materials Park, OH, 2000, pp. 495-500.

[4] L. Pawlowski, The relationship between structure and dielectric properties in plasma-sprayed alumina coatings, Surface and Coating Technology 35 (1988) 285-298.

[5] P. Ctibor, et al., Plasma spraying of titanates-I, in: C. Berndt (Ed.), Proc. of the First International Thermal Spray Conference, ASM International, Materials Park, OH, 2000, pp. 945-950.

[6] K. Neufuss, A. Rudajevova, Thermal properties of the plasmasprayed $\mathrm{MgTiO}_{3}-\mathrm{CaTiO}_{3}$ and $\mathrm{CaTiO}_{3}$, Ceramics International 28 (1) (2002) 93-97.

[7] P. Ctibor, J. Sedláček, Dielectric properties of plasma sprayed titanates, Journal of European Ceramic Society 21 (2001) 1685-1688.

[8] Gmelins Handbook of Inorganic Chemistry, vols. 41-42, Leipzig, 1951 (in German).

[9] H. Landolt, R. Boernstein, Values and Functions in Physics, Chemistry, Astronomy, Geophysics and Technology, Vol. IV, Part 3, Springer Verlag, Berlin, 1957, (in German).

[10] A. Bauer, Technology and application of ferroelectrics, Leipzig, 1976 (in German).

[11] P. Chraska, M. Hrabovsky, An overview of water stabilized plasma guns and their applications, in: C. Berndt, (Ed.), Proc. of the Int. Thermal Spray Conf. 1992, Orlando, FL, USA, 1992, pp. $81-85$.

[12] J. Ilavsky, et al., Influence of spray angle on the pore and crack microstructure of plasma-sprayed deposits, Journal of American Ceramic Society 80 (1997) 733-742.

[13] Czech Standard CSN IEC 250, Czech Institute for Standardization, Prague, 1997 (in Czech).

[14] P. Ctibor, Study of the Structure and Properties of Plasma Deposits of Perovskite-related Ceramics, PhD thesis, CTU, Prague, 2000 (in Czech).

[15] US Standard ASTM D 257-66.

[16] N.E. Hill, Dielectric Properties and Molecular Behaviour, Van Nostrand-Reinhold, London, 1969. 